\title{
THE CHARACTERISTICS OF SOME ALMOND AND ALLIED OILS.
}

By Dr. J. Lewrowitsch, F.I.C.

(Read at the Meeting, December 2, 1903.)

A нiтhento unsolved problem in fat analysis is the detection of apricot and peach kernel oils in almond oil. The ordinary quantitative reactions applied in fat analysis are of hardly any use here.

It is well known that most of the commercial "almond oil "is apricot kernel oil, and in the trade an oil described as "oil of sweet almonds, French" (oleum amygdalarum gallicum), is nothing else but apricot kernel oil or pesch kernel oil. Genuine almond oil is sold under the name of "almond oil, English."

Through the kindness of Mr. Brewis and Mr. W. C. Allen, I have been placed in possession of several samples of almond oils, apricot kernel oils, and peach kernel oils of undoubted genuineness (Nos. 2 to 9 in the following table). It may perhaps be useful to collate the numbers which are usually ascertained in the examination of fats. 
I have added the values obtained for a genuine sample prepared for me some ten years ago by a German firm from pure Valencia almonds.

\begin{tabular}{|c|c|c|c|c|c|c|c|c|c|}
\hline \multirow{2}{*}{$\begin{array}{l}\text { Description } \\
\text { of Oil. }\end{array}$} & \multirow{2}{*}{ 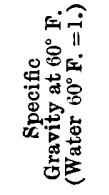 } & \multirow{2}{*}{ 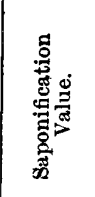 } & \multirow{2}{*}{ 量 } & \multirow{2}{*}{ 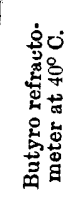 } & \multirow{2}{*}{ 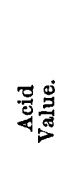 } & \multicolumn{2}{|c|}{ FATTY ACIDS. } & \multirow{2}{*}{\multicolumn{2}{|c|}{ Colour Tests. }} \\
\hline & & & & & & ⿶્ּ & غ્ટ் & & \\
\hline $\begin{array}{l}\text { Almond oils, } \\
\text { expressed } \\
\text { from : }\end{array}$ & & & & & & & & Bieber's Test. & $\begin{array}{c}\text { Phloroglucinol } \\
\text { Test. }\end{array}$ \\
\hline $\begin{array}{l}\text { 1. Valencia } \\
\text { sweets }\end{array}$ & 0.91995 & $207 \cdot 6$ & $99 \cdot 4$ & $57 \cdot 5$ & $5 \cdot 16$ & $207 \cdot 8$ & $207 \cdot 6$ & Colourless & No coloration \\
\hline $\begin{array}{l}\text { 2. Blanched } \\
\text { Valencia } \\
\text { sweets }\end{array}$ & 0.9182 & $191 \cdot 7$ & $103 \cdot 6$ & $57 \cdot 5$ & $2 \cdot 9$ & $196 \cdot 4$ & $201 \cdot 7$ & Colourless & $\begin{array}{l}\text { No crimson } \\
\text { coloration }\end{array}$ \\
\hline $\begin{array}{l}\text { 3. Sicily } \\
\text { sweets }\end{array}$ & 0.9178 & $183 \cdot 3$ & $100 \cdot 3$ & $57 \cdot 0$ & 0.79 & $198 \cdot 8$ & $202 \cdot 2$ & Colourless & $\begin{array}{c}\text { No crimson } \\
\text { coloration }\end{array}$ \\
\hline $\begin{array}{l}\text { 4. Mazagan } \\
\text { bitters }\end{array}$ & 0.9180 & $188^{\circ} 6$ & $102 \cdot 5$ & $56 \cdot 5$ & $3 \cdot 1$ & $196 \cdot 8$ & $203 \cdot 1$ & Colourless & $\begin{array}{l}\text { Slightly } \\
\text { crimson }\end{array}$ \\
\hline $\begin{array}{l}\text { 5. Small } \\
\text { Indian } \\
\text { almonds }\end{array}$ & 0.91907 & $189 \cdot 2$ & $96 \cdot 65$ & $57 \cdot 0$ & $2 \cdot 9$ & $195 \cdot 8$ & $200 \cdot 7$ & Colourless & $\begin{array}{l}\text { Slightly } \\
\text { crimson }\end{array}$ \\
\hline $\begin{array}{l}\text { 6. Mogador } \\
\text { bitters }\end{array}$ & 0.9183 & $194 \cdot 98$ & $104 \cdot 2$ & $57 \cdot 0$ & $1 \cdot 3$ & $197 \cdot 1$ & $203 \cdot 2$ & Colourless & $\begin{array}{l}\text { No crimson } \\
\text { coloration }\end{array}$ \\
\hline $\begin{array}{l}\text { 7. Peach ker- } \\
\text { nel oil }\end{array}$ & 0.9198 & $191 \cdot 4$ & $95 \cdot 24$ & $57 \cdot 5$ & $3 \cdot 0$ & $196 \cdot 8$ & $205^{\circ} 0$ & $\begin{array}{l}\text { Colourless at } \\
\text { first, then }\end{array}$ & $\begin{array}{l}\text { Deep crimson } \\
\text { coloration }\end{array}$ \\
\hline 8. Apricot & 0.9200 & $192 \cdot 4$ & $107 \cdot 4$ & $58 \cdot 0$ & $2 \cdot 3$ & $198^{\circ} 0$ & $202 \cdot 0$ & $\begin{array}{l}\text { Pink colora- } \\
\text { tion }\end{array}$ & $\begin{array}{l}\text { Deep crimson } \\
\text { coloration }\end{array}$ \\
\hline $\begin{array}{l}\text { 9. Apricot } \\
\text { kernel oil } \\
\text { from } \\
\text { Mogador } \\
\text { kernels }\end{array}$ & 0.9172 & $198 \cdot 2$ & $107 \cdot 9$ & $57 \cdot 0$ & $2 \cdot 8$ & $194 \cdot 0$ & $200 \cdot 7$ & Slightly pink & $\begin{array}{l}\text { Less deep } \\
\text { crimson } \\
\text { than } 8\end{array}$ \\
\hline $\begin{array}{l}\text { 10. Californian } \\
\text { apricot } \\
\text { kernel oil }\end{array}$ & 0.92026 & $190 \cdot 3$ & $108 \cdot 7$ & $58 \cdot 0$ & $1 \cdot 2$ & $197 \cdot 8$ & $202 \cdot 8$ & $\begin{array}{l}\text { Very slightly } \\
\text { pink }\end{array}$ & $\begin{array}{c}\text { Less deep } \\
\text { crimson } \\
\text { than } 8\end{array}$ \\
\hline
\end{tabular}

Mr. Ross, to whom my best thanks are due, was kind enough to determine the refractive indices of the ten oils for different rays. Unfortunately, the numbers given below do not furnish an analytical means of differentiating almond oil from the related oils.

Refractive Indices at $20^{\circ}$ Centigrade.

\begin{tabular}{|c|c|c|c|c|c|}
\hline 1.4715 & & $1 \cdot 4688$ & & $\begin{array}{c}\mathrm{F} . \\
1 \cdot \dot{4} 80\end{array}$ & \\
\hline 1.4715 & $\ldots$ & $1 \cdot 4688$ & $\ldots$ & 1.4780 & $\ldots$ \\
\hline $1 \cdot 4711$ & $\ldots$ & $1 \cdot 4685$ & $\ldots$ & $1 \cdot 4777$ & $\ldots$ \\
\hline $1 \cdot 4712$ & $\ldots$ & $1 \cdot 4686$ & $\ldots$ & $1 \cdot 4778$ & $\ldots$ \\
\hline $1 \cdot 4710$ & $\ldots$ & $1 \cdot 4685$ & $\ldots$ & $1 \cdot 4777$ & $\ldots$ \\
\hline $1 \cdot 4714$ & $\ldots$ & $1 \cdot 4688$ & $\ldots$ & 1.4780 & $\ldots$ \\
\hline 1.4710 & $\ldots$ & $1 \cdot 4685$ & $\ldots$ & $1 \cdot 4776$ & $\ldots$ \\
\hline $1 \cdot 4717$ & $\ldots$ & $1 \cdot 4692$ & $\ldots$ & $1 \cdot 4784$ & . \\
\hline $1 \cdot 4715$ & $\ldots$ & $1 \cdot 4690$ & $\ldots$ & $1 \cdot 4782$ & $\ldots$ \\
\hline $1 \cdot 4725$ & $\ldots$ & $1 \cdot 4700$ & $\ldots$ & $1 \cdot 4792$ & $\ldots$ \\
\hline
\end{tabular}


It will be seen that no information of a discriminative nature can be gained from the figures contained in the foregoing tables. Recourse must therefore be had to colour reactions. Much in vogue, and in fact the ouly one that gives some indications, is Bieber's test. This consists in treating 5 measures of the oil with 1 measure of a mixture consisting of equal parts (by weight) of sulphuric acid, fuming nitric acid, and water.

Pure almond oil does not change colour, whereas peach kernel oil assumes a peach-blossom tint.

It is best to prepare Bieber's reagent afresh for each set of tests. It should also be noted that the colour reaction is much stronger in the case of fresh oil than with a sample which has been kept for half a year or longer.

Mixtures of almond oil and apricot kernel oil containing one-third of the latter are coloured distinctly, but mixtures containing 25 per cent. of apricot oil only slightly, so that it would be certainly somewhat hazardous to pronounce adulteration on the strength of this colour test. Peach kernel oil gives the same colour reaction, but in a much fainter degree, and only after standing for some time. It will be more risky still to judge from this test as to adulteration of a given sample of almond oil.

Maben's statements as to the differences in the elaidin tests are unfounded. Although with concentrated sulphuric acid apricot and peach kernel oils give darker colorations than almond oil, this test is perfectly useless. The same criticism holds good with regard to Maben's zinc chloride test.

Recently, phloroglucinol* in $\frac{1}{10}$ per cent. ether solution in the presence of nitric acid, specific gravity $1 \cdot 45$, has been proposed as a test for apricot kernel and peach kernel oils. Undoubtedly, apricot kernel oil and peach kernel oil give a distinct deep crimson coloration with the reagent, in contradistinction to some almond oils; yet some specimens of the above-described genuine almond oils show more or less strongly the same reaction. This test must therefore be employed with the utmost care.

Unfortunately, the quantities at my disposal did not permit me to examine the fatty acids, especially the liquid fatty acids, as thoroughly as I could have wished, since it may be hoped that differences between almond oils and the other oils can be established in the yield of the tetrabromides, the differences in the iodine numbers of the oils becoming much more pronounced in the liquid fatty acids than in the mixed fatty acids.

I have added in the last two columns of the table the neutralization and saponification numbers of the fatty acids. These were ascertained, together with those of many other fatty acids, in view of Tortelli's and Pergami's statement that nearly all fatty acids contain small quantities of lactonic substances. These numbers will be published elsewhere, and I must content myself with stating that the experimental numbers did not wholly bear out the statements of those chemists; in fact, in some cases the difference between the saponification and neutralization number was a negative one, the difference exceeding the experimental values. The numbers given for the first almond oil bring out the same fact.

Dieterich states that by Crismer's method of determining the critical temperature

$$
\text { * Chwolles, Pharm. Zeit., 1903, p. } 109 .
$$


of dissolution differences between almond and the allied oils are observed. I have not yet been able to verify this experimentally.

\section{Discussion.}

The President (Mr. Fairley) having invited discussion,

Mr. E. T. BrewIs said that in $1890 \mathrm{Mr}$. W. C. Allen and he had examined a series of oils from known sources [Pharm. Journ. (IV.), vol. xi., p. 87] similar to those with which they had been able to provide Dr. Lewkowitsch, and their conclusions from the figures then obtained had been that the specific gravity and saponification value were not of very much assistance. It seemed possible, however, that the iodine value might afford some means of differentiating between almond oil and apricot kernel oil. The iodine values obtained were somewhat lower than those given by Dr. Lewkowitsch, but, speaking generally, the iodine value of genuine almond oil was lower than that of apricot kernel oil, while the iodine value of peach kernel oil was intermediate, but pretty close to that of almond oil. With regard to colour reactions, Bieber's test and the nitric acid test (which latter was official in the British, German, and American Pharmacopœias) gave with apricot kernel oil a deep salmon-red coloration, almond oil a white or whitish mixture, and although some specimens varied somewhat, any coloration produced with a genuine almond oil was but slight, and quite distinct from the reaction of other oils, with the exception of peach kernel oil, which gave an intermediate result. This fact had been pointed out some years previously by Mir. J. C. Umney, and he (Mr. Brewis) was able to confirm it, and he believed that Dr. Lewkowitsch had also obtained a similar result. There was, considerable misapprehension as to the peach kernel oil occurring in commerce, which he believed was originally due to an erroneous idea as to the source of the kernels used. At the time that what is now sold as peach or (and) apricot kernel oil was introduced into English commerce, the kernels were known on the market under the general name of " peach kernels," whence the term "oleum amygdala persica"viz., the oil from "the peach" (Amygdalus persica), and not, as some incorrectly translate it, "Persian almond oil."

At the present time, however, the kernels from which ol. amygd. persic. dulc. is expressed are mainly apricot kernels, of which a much larger quantity is imported than of peach kernels. The kernels themselves could now be distinguished by the difference in their appearance, the peach kernel being flat while the apricot kernel was quite plump. Apricot kernels coming from different parts of the world, such as Persian or Syrian kernels, and those from America, differed somewhat in appearance, and the oils from them also gave slightly different figures; but on the whole the iodine value of almond oil was lower than that of apricot kernel oil and peach kernel oil came in between. He could quite corroborate Dr. Lewkowitsch's experience as to the unreliability of colour tests generally. Bieber's test, however, is useful for distinguishing apricot-kernel oil from the others, if nothing else. With reference to the nitric acid test, the Pharmacopcia, after stating that in the case of almond oil no colour should be given with the mixture of water and nitric acid, went on to say that, on standing for six hours at $10^{\circ} \mathrm{C}$, a deposit should, in the case 
of almond oil, appear in the tube. He did not find that with all genuine almond oils, and he would like to see some further work done on this point, for he thought that in that respect both the British and the German Pharmacopceias were hardly correct.

Mr. Allen inquired whether Dr. Lewkowitsch insisted on the strength of the nitric acid being $1 \cdot 45$, because that was a somewhat awkward strength to obtain. Acid of specific gravity 1.42 distilled unchanged, while 1.50 to 1.52 was what was termed fuming nitric acid. Both of these were commonly readily available, but 1.45 acid was an intermediate strength which would usually have to be specially prepared. He gathered from Dr. Lewkowitsch's demonstration that it did not much matter how much of the phloroglucinol solution or how much of the nitric acid was used. He quite agreed with Mr. Brewis as to the misapprehensions which existed in commerce with regard to these oils, and which often caused much difficulty in dealing with such cases. Probably it would be best if almond oil were defined as the fixed oil from almonds, peach kernels or apricot kernels, for probably all three were equally useful. He was afraid that the tests laid down in the British Pharmacopœia for distinguishing between almond oil and peach kernel oil or apricot kernel oil were not to be regarded as trustworthy. He would like to see described as genuine any oil derived from the same botanical family and having the same therapeutic value and the same physical characters, though probably further research might lead to the establishment of a correct method for differentiating between these very closely allied oils.

Dr. Schidrowitz inquired whether any particular difference had been found to exist between ordinary expressed almond oils and oils extracted by ether. The point, perhaps, was not one of any importance commercially, but from an analytical point of view it sometimes might be. $\mathrm{He}$ had recently had to examine two samples of ground almonds to ascertain if they were adulterated, and, having extracted some of the oil, had obtained therefrom results which corresponded fairly well with those now given by Dr. Lewkowitsch. With some of the colour tests the samples had certainly given different results. In one case the Bieber test gave a faint reaction, and in the other none. The same applied to the zinc chloride test and the nitric acid test. The only important difference, however, between the two samples, beyond a decided difference in taste, was in the acidity of the almonds themselves. One of the samples, on direct titration, showed an acidity equivalent to 1.06 per cent. of oleic acid, and the other an acidity equivalent to 0.77 per cent. But after standing for a few days, the acidity in the first case had increased to 3.4 per cent., and in the other case to 1.23 per cent. Curiously enough, in the case of the sample with the higher acidity the saponification and iodine values of the extracted oil were less satisfactory than in the other sample.

Dr. Lewkowitsch said the point he had wished to raise was not so much the differentiation of almond oil from apricot kernel oil - which, taking all tests together, would seem to be not very difficult-but the detection of admixtures of, say, 20 per cent. or 30 per cent. of these oils to almond oil, a question which was sometimes put before the analyst, and which was very difficult to decide. As to the strength of nitric acid to be used, he did not lay down any fixed strength. So long as one did not know what was the chromogenic substance which caused the colour reaction, as in the case of sesamé oil, such tests were really more or less valueless. In the 
present case the suitability of acid of 1.45 strength was more or less of the nature of a compromise; 1.5 acid caused the ether to boil and spoiled the test, whereas in 1.4 acid there was insufficient nitrous acid; hence a few drops more or less might be required in different cases. He was afraid that, in the matter referred to by Dr. Schidrowitz, chemistry would not be able to afford much assistance. Microscopical examination and taste would give more information in such a case than any chemical test. It would be quite intelligible that the more bitter sample should have a greater acidity, and hence should become more strongly rancid, very likely in consequence of hydrolysis set up by a ferment.

Dr. Voelcker inquired whether there was any marked difference in commercial value between almond oil and peach kernel or apricot kernel oil, or any difference in properties which made an admixture undesirable.

Dr. Lewkowitsch said that he personally could not see that any great harm would be done to a buyer by supplying him with apricot kernel oil or peach kernel oil instead of almond oil, but, of course, almond oil was the dearer oil.

Mr. BREwIs said that the wholesale price of peach kernel oil was from $7 \mathrm{~d}$. to $9 \mathrm{~d}$. per pound, while that of almond oil was from 1s. 4d. to 1s. 8d. Apart from the question of price, a sharp commercial distinction was drawn between almond oil and peach kernel (and) or apricot kernel oil, and very little peach kernel oil as such occurred in the market at all. 